\title{
Cerium oxide-chitosan based nanobiocomposite for food borne mycotoxin detection
}

\author{
Ajeet Kaushik, ${ }^{1,2}$ Pratima R. Solanki, ${ }^{1}$ M. K. Pandey, ${ }^{1}$ Sharif $A$ hmad, ${ }^{2}$ and \\ Bansi D. Malhotra ${ }^{1,3, a)}$ \\ ${ }^{1}$ Department of Science and Technology Centre on Biomolecular Electronics, National Physical Laboratory, \\ New Delhi 110012, India \\ ${ }^{2}$ Department of Chemistry, Materials Research Laboratory, Jamia Millia Islamia, New Delhi 110025, India \\ ${ }^{3}$ Centre for Nano-Bioengineering and Spintronics, Chungnam National University, Daejeon 305-764, \\ Republic of Korea
}

(Received 11 September 2009; accepted 21 September 2009; published online 29 October 2009)

\begin{abstract}
Cerium oxide nanoparticles $\left(\mathrm{NanoCeO}_{2}\right)$ and chitosan $(\mathrm{CH})$ based nanobiocomposite film deposited onto indium-tin-oxide coated glass substrate has been used to coimmobilize rabbit immunoglobin (r-IgGs) and bovine serum albumin (BSA) for food borne mycotoxin [ochratoxin-A (OTA)] detection. Electrochemical studies reveal that presence of $\mathrm{NanoCeO}_{2}$ increases effective electro-active surface area of $\mathrm{CH}-\mathrm{NanoCeO}_{2}$ /indium tin oxide (ITO) nanobiocomposite resulting in high loading of r-IgGs. BSA/r-IgGs/CH-NanoCeO $/ 2$ ITO immunoelectrode exhibits improved linearity $(0.25-6.0 \mathrm{ng} / \mathrm{dl})$, detection limit $(0.25 \mathrm{ng} / \mathrm{dl})$, response time $(25 \mathrm{~s})$, sensitivity $\left(18 \mu \mathrm{A} / \mathrm{ng} \mathrm{dl}^{-1} \mathrm{~cm}^{-2}\right)$, and regression coefficient $\left(\mathrm{r}^{2} \sim 0.997\right)$. (C) 2009 American Institute of Physics. [doi:10.1063/1.3249586]
\end{abstract}

Electrochemical immunosensors due to accuracy, sensitivity, selectivity and cost-effectiveness have been extensively used to detect proteins, biomarkers, biological toxins, and biological-warfare agents in critical situations, food, environment, pharmaceutical chemistry, and clinical diagnostics. ${ }^{1-3}$ The choices of nanomaterials as appropriate matrices due to unique optical, electrical, and molecular properties and in particular high reactivity and beneficial chemically tailored physicochemical properties have been utilized for antibodies immobilization with proper orientation that help to obtain sensitive, compact, and stable immunosensor. ${ }^{2,3}$

Among nanomaterials, metal oxides have been found to exhibit high surface-to-volume ratio, high surface reaction activity, high catalytic efficiency, and strong adsorption ability that make them potential candidate materials for the fabrication of biosensor. ${ }^{2-5}$ Among these, nanostructured $\mathrm{CeO}_{2}$ due to high mechanical strength, oxygen ion conductivity, biocompatibility, oxygen storage capacity, nontoxicity, high chemical stability and high electron transfer have aroused much interest for development of implantable biosensors. Moreover, high isoelectric point (IEP) of $\mathrm{CeO}_{2}(\sim 9.2)$ can be helpful to immobilize desired biomolecules of low IEP via electrostatic interactions. ${ }^{2,5-13}$

Nanostructured $\mathrm{CeO}_{2}$ has been used for various biosensor applications such as immunosensor for mycotoxin, ${ }^{2}$ to immobilize cholesterol oxidase/glucose oxidase to detect cholesterol/glucose ${ }^{5-7}$ as an insoluble oxidant to minimize interferents, ${ }^{8}$ for hydrogen peroxide detection via immobilizing horseradish peroxidase, ${ }^{9,10}$ and DNA hybridization detection. ${ }^{11}$ However, there is a considerable scope to improve the biosensing characteristics of $\mathrm{NanoCeO}_{2}$ by dispersing these in electroactive biopolymer e.g., chitosan $(\mathrm{CH})$ to fabricate nanobiocomposite. $\mathrm{CH}$ due to its excellent film-

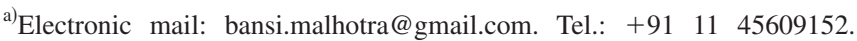
FAX: +91 1145609310 .
}

forming ability, mechanical strength, biocompatibility, nontoxicity, susceptibility to chemical modification, costeffectiveness, etc., has been explored for biosensor development. ${ }^{3}$ Moreover, amino groups of $\mathrm{CH}$ provide a hydrophilic environment compatible with the biomolecules. ${ }^{3,14}$ In this context, nanoporous $\mathrm{CH}-\mathrm{NanoCeO}_{2}$ composite has been used to fabricate DNA and cholesterol biosensor. ${ }^{12,13}$

We report results of studies relating to coimmobilization of $\mathrm{r}-\mathrm{IgG}$ and $\mathrm{BSA}$ onto $\mathrm{CH}-\mathrm{NanoCeO}_{2}$ nanobiocomposite film onto indium-tin-oxide coated glass substrate for OTA detection. $\mathrm{BSA} / \mathrm{r}-\mathrm{IgGs} / \mathrm{CH}-\mathrm{NanoCeO} /$ indium tin oxide (ITO) immunosensor shows improved sensing characteristics. OTA is produced by several species of Aspergillus and Penicillium and occurs in a variety of food commodities that causes nephrotoxin, hepatotoxin, teratogen, and carcinogen (group 2B, possibly by induction of oxidative DNA damage). ${ }^{2,3}$

All chemicals of analytical grade were purchased from Sigma Aldrich. $1 \mathrm{gm}$ of cerium ammonium nitrate was dissolved in distilled $20 \mathrm{ml}$ de-ionized water. $\mathrm{NanoCeO}_{2}$ $(10 \mathrm{mg})$, synthesized using co-precipitation ${ }^{13}$ method is dispersed in $10 \mathrm{ml}$ of $\mathrm{CH}$ solution [prepared by dissolving $50 \mathrm{mg} \mathrm{CH}$ in $10 \mathrm{ml}$ of acetate buffer $(0.05 \mathrm{M}, p \mathrm{H} 4.2)$ solution] by constant stirring at room temperature $\left(25^{\circ} \mathrm{C}\right)$. The nanocomposite films are fabricated by uniformly spreading $10 \mu \mathrm{l}$ solution of $\mathrm{CH}-\mathrm{NanoCeO} \mathrm{Ce}_{2}$ nanobiocomposite onto an ITO $\left(0.25 \mathrm{~cm}^{2}\right)$ surface and dried at room temperature for about $12 \mathrm{~h}$ and then washed with deionized water to remove any unbound particles. OTA (Aspergillus ochraceus) solution is prepared in phosphate buffer $(\mathrm{PB}, 50 \mathrm{mM}, p \mathrm{H}$ 7.0) with $10 \%$ methanol. Solution of $\mathrm{r}$-IgGs is prepared in PB. The immobilization of $r-\operatorname{IgG}$ has been carried out by spreading $10 \mu \mathrm{l}$ solution onto the $\mathrm{CH}-\mathrm{NanoCeO}_{2}$ nanobiocomposite electrode. BSA (98\%) dissolved in PB is used as the blocking agent for nonspecific binding sites. Both the solutions containing $0.015 \mathrm{M} \mathrm{NaN}$ as a preservative are aliquoated and stored at $-20{ }^{\circ} \mathrm{C}$. 

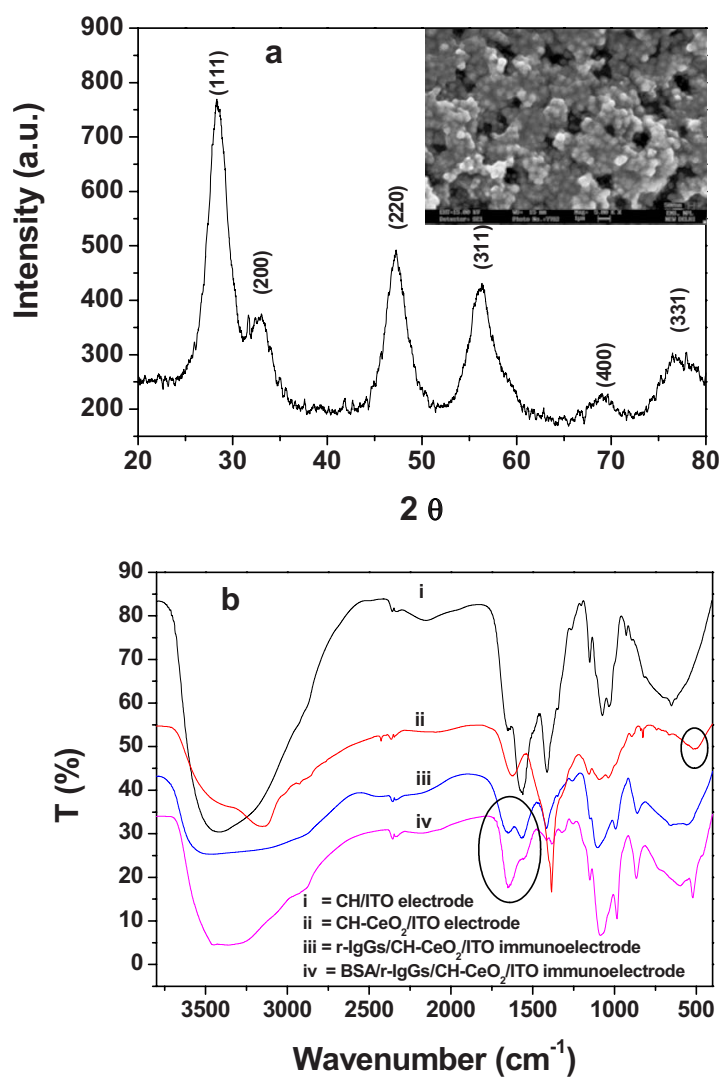

FIG. 1. (Color online) (a) XRD pattern of $\mathrm{NanoCeO}_{2}$. Inset: SEM image of $\mathrm{CH}-\mathrm{NanoCeO} / \mathrm{ITO}$ nanobiocomposite. (b) FTIR spectra of both $\mathrm{CH} / \mathrm{ITO}$ electrode (curve i), $\mathrm{CH}-\mathrm{NanoCeO}_{2} / \mathrm{ITO}$ electrode (curve ii), r-IgGs/CHNanoCeO ${ }_{2} /$ ITO immunoelectrode (curve iii), and $\mathrm{BSA} / \mathrm{rIgGs} / \mathrm{CH}-\mathrm{Nano}-\mathrm{CeO}_{2} / \mathrm{ITO}$ immunoelectrode (curve iv).

X-ray diffraction studies (XRD) (Rigaku, miniflux 2) have been used to confirm formation of $\mathrm{CeO}_{2}$ nanoparticles. Scanning electron microscope (SEM) (LEO-440), Fourier transform infrared (FTIR) (Perkin Elmer) and Autolab (Potentiostat/Galvanostat) are used to characterize electrodes and immunoelectrodes. The electrochemical studies [differential pulse voltammetry (DPV) and cyclic voltammetry $(\mathrm{CV})]$ are carried out in phosphate buffer saline $(50 \mathrm{mM}$ and $0.9 \% \mathrm{NaCl})$ containing $5 \mathrm{mM}\left[\mathrm{Fe}(\mathrm{CN})_{6}\right]^{3-14-}$ at $p \mathrm{H} 7$, at this $p \mathrm{H}$ biomolecule retains its natural structure and activity.

XRD pattern [Fig. 1(a)] of the $\mathrm{CeO}_{2}$, synthesized using coprecipitation method exhibits characteristic diffraction planes corresponding to $\mathrm{CeO}_{2}$ fluorite structure. ${ }^{2,15}$ However, the observed reflection planes are broad due to small particle size $(\sim 10 \mathrm{~nm})$ estimated using Scherrer's formula. The incorporation of $\mathrm{NanoCeO}_{2}$ in $\mathrm{CH}$ matrix has been confirmed using SEM wherein, regular planner morphology of $\mathrm{CH}$ (Ref. 3) changes into globular nanoporous morphology [inset, Fig. 1(a)] due to uniform distribution of $\mathrm{NanoCeO}_{2}$ in $\mathrm{CH}$ matrix via electrostatic interaction.

FTIR spectra of $\mathrm{CH}-\mathrm{NanoCeO}_{2}$ nanobiocomposite [Fig. 1(b), curve ii] shows characteristic bands corresponding to $\mathrm{CH}$ (curve i) and the $\mathrm{NanoCeO}_{2}$ revealing the formation of nanocomposite. The band at $\sim 465 \mathrm{~cm}^{-1}$ assigned to $\mathrm{Ce}-\mathrm{O}$ stretching in $\mathrm{CeO}_{2}$ nanoparticles ${ }^{13}$ shifts to $505 \mathrm{~cm}^{-1}$ (curve b) in $\mathrm{CH}-\mathrm{NanoCeO}_{2}$ nanobiocomposite due to electrostatic interactions between $\mathrm{CH}$ and $\mathrm{NanoCeO}_{2}$. The bands at 1643 and $1560 \mathrm{~cm}^{-1}$ observed in FTIR spectra of r-IgGs/CH-NanoCeO $\mathrm{O}_{2} / \mathrm{ITO}$ immunoelectrode (circle, curve iii) correspond to amide II band of $\mathrm{r}$-IgGs ( $\beta$-sheet, main
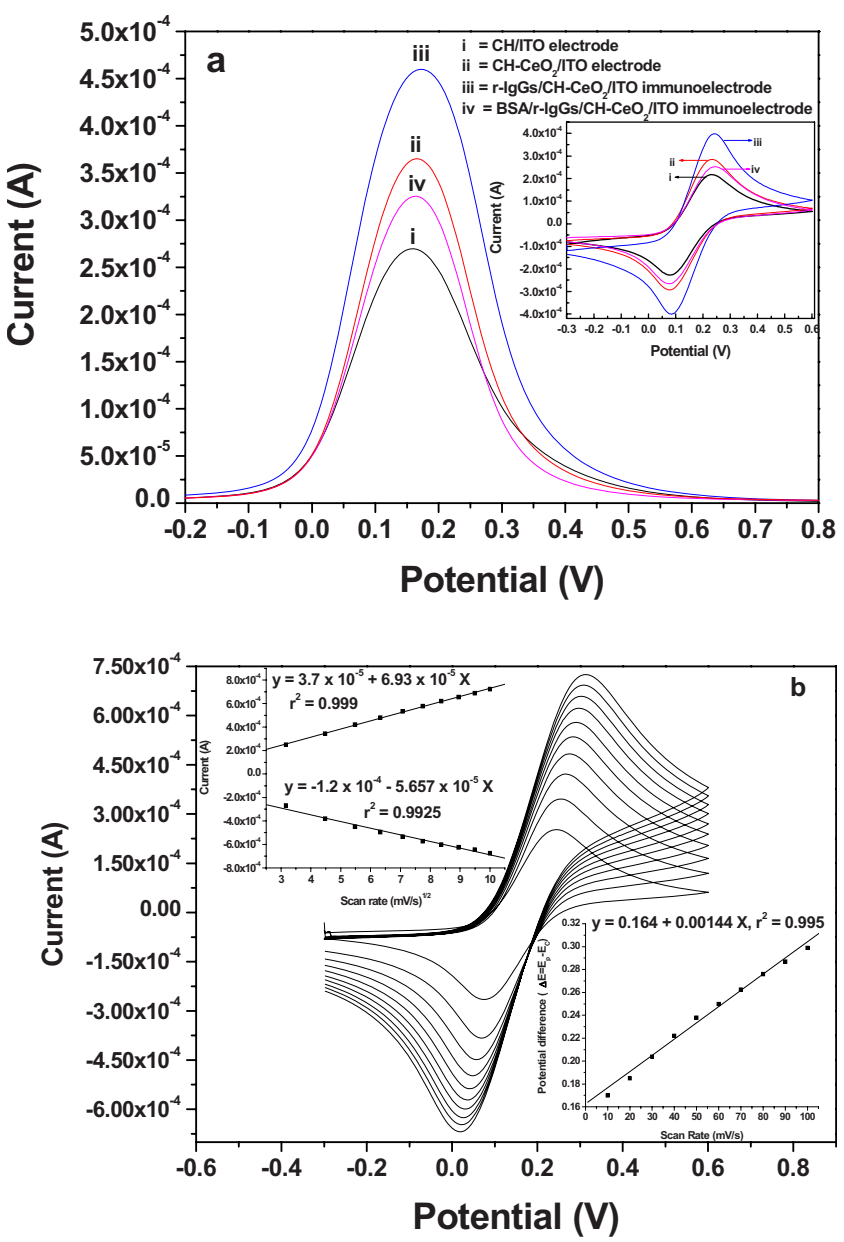

FIG. 2. (Color online) (a) DPV studies of $\mathrm{CH} / \mathrm{ITO}$ electrode (curve i), $\mathrm{CH}-\mathrm{NanoCeO}_{2} / \mathrm{ITO}$ electrode (curve ii), r-IgGs/CH-NanoCeO $\mathrm{C}_{2} / \mathrm{ITO}$ immunoelectrode (curve iii), and $\mathrm{BSA} / \mathrm{r}-\mathrm{IgGs} / \mathrm{CH}-\mathrm{Nano}-\mathrm{CeO}_{2} / \mathrm{ITO}$ immunoelectrode (curve iv). Inset: $\mathrm{CV}$ studies of the stepwise formation of $\mathrm{BSA} / \mathrm{r}-\mathrm{IgGs} / \mathrm{CH}-\mathrm{NanoCeO}_{2} / \mathrm{ITO}$ immunoelectrode. (b) $\mathrm{CV}$ studies of $\mathrm{BSA} / \mathrm{r}$-IgGs/CH-NanoCeO $/ 2$ ITO immunoelectrode as a function of scan rate $(10-100 \mathrm{mV} / \mathrm{s})$.

secondary structure element of IgGs), indicating immobilization of r-IgGs. However, presence of sharp band at $1647 \mathrm{~cm}^{-1}$ in $\mathrm{BSA} / \mathrm{r}-\mathrm{IgGs} / \mathrm{CH}-\mathrm{NanoCeO}_{2} / \mathrm{ITO}$ immunoelectrode (circle, curve iv) corresponds to amide II band of BSA indicating immobilization of BSA.,3 It is known that,

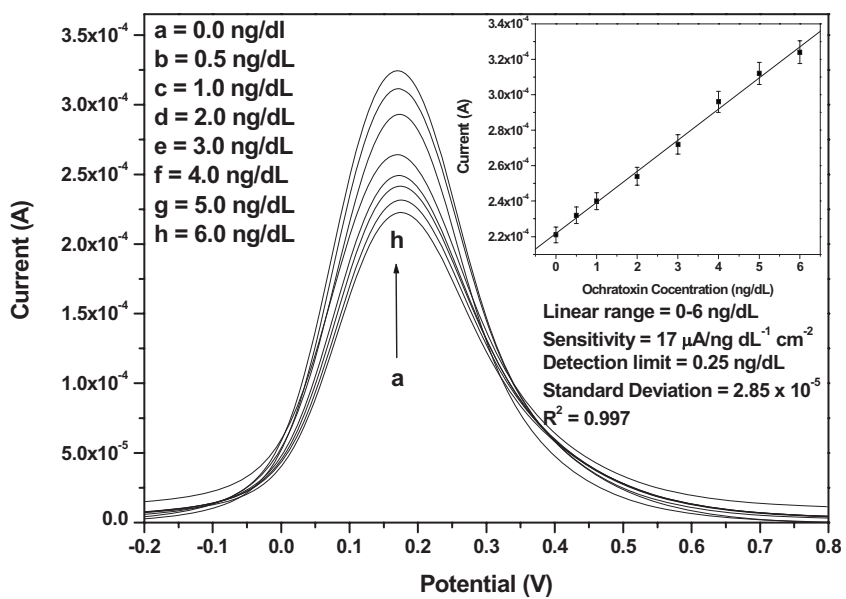

FIG. 3. Electrochemical response of BSA/r-IgGs/CH-NanoCeO $/ 2 / \mathrm{ITO}$ immunoelectrode as function of OTA concentration, inset: calibration curve between electrochemical response current and OTA concentration. 
in the $\mathrm{CH}-\mathrm{NanoCeO} \mathrm{O}_{2}$ nanobiocomposite, $\mathrm{CH}$ with positively $\mathrm{NH}_{3}^{+}$group and surface charged $\mathrm{NanoCeO}_{2}(\mathrm{IEP} \sim 9.2)$ bind with carboxyl terminated group [fragment crystalizable $\left(F_{c}\right)$ ] of r-IgGs via electrostatic interactions and the free amino terminated site [fragment antigen binding (Fab)] part is free to bind with carboxylic group of OTA.

In the DPV studies [Fig. 2(a)], the magnitude of current response for $\mathrm{CH}-\mathrm{NanoCeO}_{2} / \mathrm{ITO}$ nanobiocomposite electrode (curve ii) is higher than that of $\mathrm{CH} / \mathrm{ITO}$ electrode (curve i) revealing that presence of $\mathrm{NanoCeO}_{2}$ results in increased electro-active surface area leading to increased adsorption of redox species [Fe (III)/(IV)]. The presence of $\mathrm{NanoCeO}_{2}$ in nanobiocomposite results in improved electronic and ionic transport due to uniformly distributed $\mathrm{NanoCeO}_{2}$ within $\mathrm{CH}$ matrix rather than clustered matrix (SEM analysis) resulting in three-dimensional electron conductive network extended throughout the ion-conductive matrix of $\mathrm{CH}$. The surface concentration of redox species onto CH-NanoCeO ${ }_{2} /$ ITO electrode $\left(2.2 \times 10^{-6} \mathrm{~mol} \mathrm{~cm}^{-3}\right)$ is higher than that of $\mathrm{CH} / \mathrm{ITO}\left(1.4 \times 10^{-6} \mathrm{~mol} \mathrm{~cm}^{-3}\right)$ suggesting that incorporation of $\mathrm{NanoCeO}_{2}$ increases electroactive surface area for diffusion of electrons resulting in high electrocatalytic properties of nanobiocomposite that may be responsible for improved sensing characteristics due to high loading of r-IgGs.

The magnitude of current for r-IgGs/ CH-NanoCeO ${ }_{2}$ /ITO nanobiocomposite electrode (curve iii) further increases due to available free $\mathrm{NH}_{3}^{+}$group on r-IgGs resulting in increased adsorption of redox species. The magnitude of current decreases for $\mathrm{BSA} / \mathrm{r}-\mathrm{IgGs} / \mathrm{CH}-\mathrm{NanoCeO}_{2} / \mathrm{ITO}$ immunoelectrode (curve iv) revealing that blocking of non-binding sites of r-IgGs and pores of CH-NanoCeO $/$ ITO electrode due to immobilization of BSA hinder electron transfer between the medium. The values of diffusion coefficient $(D)$ for $\mathrm{CH} / \mathrm{ITO}$ electrode, $\mathrm{CH}-\mathrm{NanoCeO}{ }_{2} / \mathrm{ITO}$ electrode, r-IgGs/CH-NanoCeO ${ }_{2} / \mathrm{ITO}$ immunoelectrode and $\mathrm{BSA} / \mathrm{r}$-IgGs/CH-NanoCeO $/$ / ITO immunoelectrode have been calculated as $2.2 \times 10^{-7}, 4.6$ $\times 10^{-7}, 7.8 \times 10^{-7}$, and $6.0 \times 10^{-7} \mathrm{~cm}^{2} \mathrm{~s}^{-1}$ respectively, using Randles-Sevcik equation.

The results of CV studies conducted on both electrodes and immunoelectrode indicate similar behavior [inset, Fig. 2(a)]. Moreover, CV studies of BSA/ r-IgGs/CH-NanoCeO $/$ / ITO immunoelectrode [Fig. 2(b)] as a function of scan rate $(10-100 \mathrm{mV} / \mathrm{s})$ show that magnitude of current response exhibits linear relationship with square root of scan rate [inset, Fig. 2(b)], revealing a diffusioncontrolled process. The observed linear dependance of potential difference as a function of scan rate reveals the facile electron transfer ${ }^{16}$ and follows Eqs. (1)-(3), respectively,

$I_{p}\left(\mathrm{BSA} / \mathrm{r}-\mathrm{IgGs} / \mathrm{CH}-\mathrm{NanoCeO}_{2} / \mathrm{ITO}\right)[\mathrm{A}]=3.7 \times 10^{-5}[\mathrm{~A}]+6.93$

$\times 10^{-5}[\mathrm{~A} \mathrm{~s} / \mathrm{mV}]^{*} \mathrm{scan} \operatorname{rate}(\mathrm{mV} / \mathrm{s})^{1 / 2}$ with $R^{2}=0.984$,

$I_{c}\left(\mathrm{BSA} / \mathrm{r}-\mathrm{IgGs} / \mathrm{CHNanoCeO}{ }_{2} / \mathrm{ITO}\right)[\mathrm{A}]=-1.2 \times 10^{-4}[\mathrm{~A}]-5.66$

$\times 10^{-5}[\mathrm{~A} \mathrm{~s} / \mathrm{mV}]^{*}$ scan rate $(\mathrm{mV} / \mathrm{s})^{1 / 2}$ with $R^{2}=0.978$,

$\Delta E_{p}\left(\mathrm{BSA} / \mathrm{r}-\mathrm{IgGs} / \mathrm{CH}-\mathrm{NanoCeO}_{2} / \mathrm{ITO}\right)[\mathrm{V}]=0.164[\mathrm{~V}]$

$+0.00144[\mathrm{E} \mathrm{s} / \mathrm{m}]^{*} \mathrm{scan}$ rate $(\mathrm{mV} / \mathrm{s})$ with $R^{2}=0.99$.

It is observed that magnitude of the electrochemical response current of $\mathrm{BSA} / \mathrm{r}-\mathrm{IgGs} / \mathrm{CH}-\mathrm{NanoCeO}_{2} / \mathrm{ITO} \mathrm{immu}-$ noelectrode increases on addition of OTA (Fig. 3) due to formation of antigen-antibody complex between OTA and $\mathrm{r}$-IgGs on nanobiocomposite surface that acts as electron transfer-accelerating layer. A linear relationship (inset, Fig. 3 ) between magnitude of current and OTA concentration has been observed and follows Eq. (4).

$$
\begin{aligned}
I(A)= & 2.21 \times 10^{-4}(A)+17.5 \mu \mathrm{A} \mathrm{dL} \mathrm{ng}^{-1} \\
& \times\left[\text { OTA concentration }\left(\mathrm{ng} \mathrm{dl}^{-1}\right)\right], R^{2}=0.997 .
\end{aligned}
$$

The high value of the association constant (Ka,4 $\times 10^{12} 1 \mathrm{~mol}^{-1}$ ) reveals high affinity of r-IgGs toward OTA due to favorable conformation of r-IgGs onto nanoporous $\mathrm{CH}-\mathrm{NanaoCeO}{ }_{2}$ nanobiocomposite. The $\mathrm{CH}-\mathrm{NanoCeO}_{2} / \mathrm{ITO}$ based immunosensor exhibits improved sensing characteristics such as low detection limit of $0.25 \mathrm{ng} \mathrm{dl}^{-1}$, high sensitivity of $17.5 \mu \mathrm{A} / \mathrm{ng} \mathrm{dl}^{-1} \mathrm{~cm}^{2}$, reproducibility of 20 times and long term stability 80 days in comparison to $\mathrm{BSA} / \mathrm{r}-\mathrm{IgGs} / \mathrm{CH} / \mathrm{ITO}$ and $\mathrm{BSA} / \mathrm{r}-\mathrm{IgGs} /$ $\mathrm{NanoCeO}_{2} /$ ITO based immunosensor, that are summarized in the supplementary table. ${ }^{17}$

In summary, $\mathrm{NanoCeO}_{2}$ increases electroactive surface area of $\mathrm{CH}-\mathrm{NanoCeO} \mathrm{O}_{2}$ nanobiocomposite for the immobilization of $\mathrm{r}-\mathrm{IgGs}$ resulting in enhanced electron transport. The $\mathrm{BSA} / \mathrm{r}-\mathrm{IgGs} / \mathrm{CH}-\mathrm{NanoCeO}_{2} / \mathrm{ITO}$ immunosensor represents a new immunosensor platform for the detection of OTA and exhibits improved sensing characteristics than that of the solgel derived $\mathrm{NanoCeO}_{2}$ and $\mathrm{CH}$ based immunoelectrode and may find potential application for detection of other clinically important antigens such as aflatoxin, citrinin, etc.

We thank Director, NPL, India for facilities. A.K. is thankful to CSIR, India for the award of Senior Research Fellowship. We acknowledged financial support received form DST, India and MEST (Grant No. R32-20026), Korea.

${ }^{1}$ P. Skladal, Electroanalysis 9, 737 (1997).

${ }^{2}$ A. Kaushik, P. R. Solanki, A. A. Ansari, S. Ahmad, and B. D. Malhotra, Nanotechnology 20, 055105 (2009).

${ }^{3}$ A. Kaushik, P. R. Solanki, A. A. Ansari, S. Ahmad, and B. D. Malhotra, Electrochem. Commun. 10, 1364 (2008).

${ }^{4}$ P. R. Solanki, A. Kaushik, A. A. Ansari, and B. D. Malhotra, Appl. Phys. Lett. 94, 143901 (2009).

${ }^{5}$ A. A. Ansari, A. Kaushik, P. R. Solanki, and B. D. Malhotra, Electrochem. Commun. 10, 1246 (2008).

${ }^{6}$ A. A. Ansari, P. R. Solanki, and B. D. Malhotra, Appl. Phys. Lett. 92, 263901 (2008).

${ }^{7}$ S. Saha, S. K. Arya, S. P. Singh, K. Sreenivas, B. D. Malhotra, and V. Gupta, Biosens. Bioelectron. 24, 2040 (2009).

${ }^{8}$ S. H. Choi, S. D. Lee, J. H. Shin, J. Ha, H. Nam, and G. S. Cha, Anal. Chim. Acta 461, 251 (2002).

${ }^{9}$ A. Mehta, S. Patil, H. Bang, H. J. Cho, and S. Seal, Sens. Actuators A 134, 146 (2007).

${ }^{10}$ X. Xiao, Q. Luan, X. Yao, and K. Zhou, Biosens. Bioelectron. 24, 2447 (2009).

${ }^{11}$ W. Zhang, T. Yang, X. Zhuang, and Z. G. K. Jiao, Biosens. Bioelectron. 24, 2417 (2009).

${ }^{12}$ K. J. Feng, Y. H. Yang, Z. J. Wang, J. H. Jiang, G. L. Shen, and R. Q. Yu, Talanta 70, 561 (2006).

${ }^{13}$ B. D. Malhotra and A. Kaushik, Thin Solid Films 518, 614 (2009).

${ }^{14}$ C. Xu, H. Cai, P. He, and Y. Fang, Analyst (Cambridge, U.K.) 126, 62 (2001).

${ }^{15}$ P. Dutta, S. Pal, M. S. Seehra, Y. Shi, E. M. Eyring, and R. D. Ernst, Chem. Mater. 18, 5144 (2006).

${ }^{16}$ R. S. Nicholson and I. Shain, Anal. Chem. 36, 706 (1964).

${ }^{17} \mathrm{See}$ EPAPS supplementary material at http://dx.doi.org/10.1063/ 1.3249586 for a supplementary table. 